\section{Prevalência do uso e efeitos de recursos ergogênicos por praticantes de musculação nas academias brasileiras: uma revisão sistematizada}

\author{
Prevalence of the use and ergogenic \\ resources effects by body builders in \\ Brazilian academies: a systematic review.
}

Fabiana Ranielle de Siqueira Nogueira ${ }^{1}$

Alesandra Araújo de Souza ${ }^{1,2}$

Aline de Freitas Brito ${ }^{1,2,3}$

\begin{abstract}
Resumo
O objetivo da presente revisão sistemática foi traçar a prevalência, as formas de indicação e os efeitos adversos dos suplementos alimentares (SA) e esteroides anabólicos androgênicos (EAA), cujo uso é relatado por praticantes de musculação nas academias de ginástica do Brasil. Para desenvolvimento deste estudo foi realizada, em novembro de 2011, uma busca nas bases de dados Medline, Scielo, Bireme e Lilacs utilizando as palavras-chave: esteroides anabólicos androgênicos, suplementos nutricionais e academias de ginástica. Para ser incluído, o estudo deveria ter investigado o uso de recursos ergogênicos em academias do Brasil. De acordo com os critérios de inclusão, foram selecionadas em um primeiro momento 93 investigações, mas apenas 18 foram incluídas. Os estudos selecionados demonstraram que as regiões Sul e Sudeste são as que possuem maior número de estudos. A maior prevalência de consumo dos SA foi em Belo Horizonte (90,8\%), seguido por Vitória (70\%), Cascavel (66\%) e Curitiba (50,61\%), e os produtos mais consumidos foram: proteínas, aminoácidos e creatinas. Para os EAA, a maior prevalência encontrada foi em Belo Horizonte com 85\%, seguido por Aracaju (31\%) e Rio Grande do Sul $(24,9 \%)$. Os produtos mais utilizados foram o Decanoato de Nandrolona, a Testosterona e o Estanozolol. Os efeitos colaterais predominantes dos EAA foram surgimento de acne (46 a 94\%) e agressividade (47 a 73\%). Tanto o consumo de SA quanto o uso dos esteroides anabólicos androgênicos encontram-se exacerbados nas academias brasileiras, principalmente, na região Sudeste. Além disso, o uso abusivo dos EAA ocorre devido à falta de informações sobre suas contra indicações, repercutindo em inúmeros efeitos adversos à saúde.
\end{abstract}

\section{Palavras-chave}

Recursos ergogênicos; Suplementos alimentares; Esteroides anabólicos androgênicos; Academias de ginástica.

\footnotetext{
Abstract

Objective: The objective of the present study was to systematically review the prevalence, indicative ways, and adverse effects of ergogenic resources, such as dietary supplements (DS) and anabolic androgenic steroids (AAS), that were reported, by bodybuilders in gyms in Brazil. Methods: References search was performed in November 2011 in the Medline, SciELO, BIREME, and Lilacs data basis by the key-words: anabolic-androgenic steroids, nutritional supplements, and gyms. To be included the studies should have investigated the prevalence of the use of ergogenic resources in gyms in Brazil. Ninety-three investigations were selected, but only 18 were included. Results: The highest prevalence of DS consumption was in Belo Horizonte (90.8\%), followed by Vitoria (70\%), Cascavel (66\%) and Curitiba (50.61\%). For the AAS use, the highest prevalence was in Belo Horizonte with 85\%, followed by Aracaju (31\%) and Rio Grande do Sul (24.9\%). The products mainly consumed as DS were: derived proteins, amino acids and creatine. The most widely used AAS increase were Deca-Durabolin, Sustanon and Winstrol. Side effects mostly observed by the AAS users were the appearance of acne (46 to 94\%) and aggressiveness (47 to 73\%). Conclusion: Both the use of DS and AAS are exacerbated in the gyms of Brazil, mainly in the Southeast. In addition, the abuse of $A A S$ is due to a lack of information about their contraindications, resulting in innumerous adverse health effects.
}

\section{Keywords}

Resource ergogenic dietary supplements; Anabolic androgenic steroids; Gyms.
Rev Bras Ativ Fis Saúde p. 16-30 DOI: http://dx.doi.org/10.12820/23171634.2013v18n1p16

1 Laboratório de Estudos do Treinamento Físico Aplicado ao Desempenho e à Saúde, Universidade Federal da Paraíba, João Pessoa, PB, Brasil.

2 Departamento de Educação Física, Universidade Federal da Paraíba, João Pessoa, PB, Brasil.

3 Programa de Pós-Graduação em Produtos Naturais e Sintéticos Bioativos do Centro de Ciências da Saúde da Universidade Federal da Paraiba (UFPB). 


\section{INTRODUÇÃO}

A Associação Brasileira de Academias (ACAD) estima que 2,8 milhões de brasileiros sejam praticantes de musculação em academias de ginástica. ${ }^{1} \mathrm{Tal}$ fato pode ser visto como promoção de melhoria da saúde, uma vez que os exercícios resistidos promovem redução da pressão arterial e de tecido adiposo, assim como aumento da massa muscular. ${ }^{2,3}$ Por outro lado, constata-se que nas academias há a venda de substâncias denominadas recursos ergogênicos, como os suplementos alimentares (SA) e esteroides anabólicos androgênicos (EAA). ${ }^{4}$ Os SA são produtos constituídos de vitaminas, minerais, extratos, aminoácidos, metabólicos ou combinações desses ingredientes, não sendo considerados como alimento convencional da dieta. ${ }^{5}$ No Brasil, os SA foram identificados, através da portaria 222 da Secretaria de Vigilância Sanitária, como "Alimentos para Praticantes de Atividades Físicas". ${ }^{6}$ Já os EAA são substâncias químicas sintetizadas a partir da testosterona. ${ }^{7}$

Estima-se que de $8^{8}$ a $55 \%{ }^{9}$ dos praticantes de musculação utilizam os EAA, enquanto que de $8^{10}$ a $70 \%{ }^{11,12}$ consomem SA, como aminoácidos ramificados ${ }^{13,14}$, creatina $^{12,15}$ ou bebidas e carboidratos. ${ }^{10,13}$ Essa alta prevalência do uso de recursos ergogênicos está acompanhada por um elevado percentual de indicação do uso através de professores ou instrutores de academias. ${ }^{16}$ Investigações apontam que apenas $20,5 \%$ dos nutricionistas sejam responsáveis pela indicação do uso de SA e EAA, enquanto que professores ou instrutores de academia indicam o uso entre $27,5^{10}$ a $43,0 \%{ }^{17}$ dos casos.

Ocorre que os educadores físicos não possuem habilitação técnico-profissional para a realização deste procedimento, o que pode implicar em uma prescrição errônea de como utilizar os SA e EAA (Lei Federal no 9.696 e Conselho Nacional de Saúde). Investigações indicam que à utilização descontrolada do SA e EAA são atribuídas consequências que vão desde efeitos colaterais muito leves - como cãibras e cansaço muscular - até prejuízos graves, como a acromegalia, síndrome metabólica, sobrecargas renais e hepáticas, alterações psicológicas, cardíacas e morfológicas (ginecomastia e aumento do clitóris), e até a morte de indivíduos. ${ }^{18,19}$

Ressalta-se ainda que a maioria dos praticantes de musculação afirma não conhecer ou poder retardar, por meio de outros medicamentos, os efeitos deletérios causados pela administração imprópria dos recursos ergogênicos. ${ }^{8}$

Deste modo, tendo em vista que a utilização de recursos ergogênicos parece possivelmente ter crescido, mesmo diante dos efeitos deletérios evidentes provocados por sua utilização imprópria, em grande parte, indicada por profissionais não habilitados para este procedimento, e considerando que os praticantes de musculação parecem não conhecer os efeitos deletérios provocados por estas substâncias, torna-se necessário fazer uma revisão sistemática sobre a prevalência, as formas de indicação e os efeitos adversos dos SA e EAA, relatados por praticantes de musculação nas academias de ginástica do Brasil.

\section{MÉTODOS}

A busca de artigos foi realizada de forma sistemática nas bases de dados online PUBMED/Medline (Medical Literature Analysis and Retrieval System Online), Scielo (Scientific Electronic Library Online), Lilacs (Literatura Latino-Americana e do Caribe de Informação em Ciências da Saúde) e Bireme (Centro Latino-Americano e do Caribe de Informação em Ciências da Saúde). Para a realização da busca nas bases de dados utilizamos os seguintes descritores: 1- academias de ginástica, 2- suplementos nutricionais, 3-esteroides anabólicos androgênicos. A utilização dos 
descritores foi realizada de acordo com a origem da base de dados. Os estudos foram avaliados independentemente por dois revisores, de forma cega. Os possíveis desentendimentos que surgiam foram sanados consensualmente. A quantidade de estudos obtidos está ilustrada detalhadamente na tabela 1 .

\section{Critérios de Elegibilidade}

Foram incluídos apenas estudos que investigaram a prevalência do uso de recursos ergogênicos em academias de ginástica no Brasil, realizados com seres humanos, sem limite de idade e com ambos os gêneros. Com base nestes critérios, foram eliminados, em uma primeira seleção, através dos títulos e resumos, os estudos realizados com animais e de revisão. Já na segunda seleção, por meio dos textos completos, foram eliminados os estudos que não investigaram apenas a prevalência do uso de recursos ergogênicos em academias de ginástica no Brasil. Assim, foram excluídos os estudos qualitativos, que investigaram a influência dos recursos ergogênicos em atletas de fisiculturismo, recuperação de patologias como câncer ou síndrome da imunodeficiência adquirida e diminuição dos riscos cardiometabólicos. Dessa forma, 15 artigos atenderam aos critérios para compor a presente revisão sistemática, dentre estes dez referentes ao consumo de SA e cinco referentes ao uso de EAA.

\section{RESULTADOS E DISCUSSÃO}

\section{Característica dos Estudos}

Com o resultado da busca dos artigos foi possível observar que as regiões Sudeste e Sul apresentaram um número maior de estudos sobre a prevalência do uso de SA e EAA, com uma quantidade de nove e seis artigos por região, respectivamente. Em contrapartida, as regiões Norte e Nordeste ainda não têm estudos sobre o tema. $\mathrm{Na}$ região Sudeste, os estados de São Paulo e Minas Gerais apresentam o maior número de pesquisas, e na região Sul foi o Paraná. A faixa etária de interesse das amostras nesses estudos foi entre 18 a 31 anos, o que caracteriza uma população de adultos jovens. Os estudos foram realizados com ambos os gêneros, com predominância do gênero masculino. Isto demonstra que a procura por estes produtos, realmente, é maior entre jovens deste gênero. Estas informações estão sumarizadas na Tabela 1.

\section{Representatividade Amostral}

O tamanho da amostra, nos 15 estudos selecionados, variou de $58^{24}$ a $506^{9}$ praticantes de musculação. Quanto aos critérios adotados, como intervalo de confiança, margem de erro e prevalência estimada, próprios para assegurar a representatividade da amostra, apenas Silva e colaboradores ${ }^{22}$ tiveram preocupação com esses parâmetros. Nesta investigação foi realizado o cálculo da amostra a ser entrevistada a partir de uma estimativa de prevalência de uso de EAA de 8\%, aceitando-se uma margem de erro de até 3\%, para um erro alfa de 0,05 e um poder de $90 \%$, o que correspondeu a um total de 307 participantes. Corroborando com a sua prevalência estimada, eles verificaram que $11,1 \%$ eram usuários de EAA, isso confirma que o seu universo amostral era representativo. Ainda com relação à representatividade, apenas o estudo de Silva e colaboradores ${ }^{22}$ adotou em sua estratificação das unidades de amostragem o modelo de conglomerado, como parâmetro para definição dos números de academias dos seus estudos. Frente ao exposto, há indícios de que a prevalência de SA e EAA no Brasil pode estar subestimada, tendo em vista que, os pesquisadores talvez não atentem para estes parâmetros com um intuito de que haja uma maior representatividade nos resultados. 


\section{Instrumento Adotado}

$\mathrm{Na}$ presente revisão, todos os estudos utilizaram questionários como forma de coleta. No entanto, a maioria destes questionários não possuía validação e as questões foram elaboradas de acordo com o objetivo de cada estudo. 4, 9, 11,13-15, 21-23,25,26 Apenas o Hirschbruch e colaboradores ${ }^{10}$ adotaram instrumento validado, o qual foi adaptado do questionário usado para triagem do uso de álcool e/ou drogas, Drug Use Screening Inventory, não adequado para estudos com recursos ergogênicos. Apesar da existência de instrumento validado internacionalmente para pesquisa sobre utilização de recursos ergogênicos ${ }^{27}$, no Brasil, ainda não há uma adaptação, construção ou validação de um questionário para realização deste tipo de pesquisa, que colete informações como variáveis sócio-demográficas (sexo, idade, escolaridade, renda) e dados comportamentais (tempo de prática, frequência da atividade, tipo de SA utilizado e/ou EAA, tempo de utilização do SA e/ou EAA, quantidade de SA utilizada e/ou EAA, modo de indicação). Assim, torna-se necessária a elaboração de um questionário que forneça informações precisas, e aplicação adequada de acordo com a característica populacional.

\section{Prevalência dos SA e EAA Mais Utilizados no Brasil}

No Brasil, atualmente, pesquisas demonstram alto percentual de consumo dos recursos ergogênicos. O perfil de prevalência dos recursos ergogênicos mais utilizados e quais as indicações de uso mais frequentes estão explanadas na Tabela 2.

\section{Prevalência de Suplementos Alimentares no Brasil}

$\mathrm{Na}$ tabela 2 é possível observar que o índice de prevalência de consumo de SA é elevado na população brasileira. De fato, os estudos de Hallak e colaboradores ${ }^{13}$, Araújo e colaboradores ${ }^{15}$, Reis e colaboradores ${ }^{23}$ identificaram percentuais de consumo que variaram de 20,5 a 81,2\%. Domingues \& Marins ${ }^{4}$ apontam o maior índice de suplementação, com um valor de aproximadamente $94 \%$. No Sudeste, foram encontrados valores de 47 e 46\% nas cidades de Campinas e Rio de Janeiro. ${ }^{25,29} \mathrm{Na}$ região Sul, especificamente na cidade de Florianópolis, o consumo entre os frequentadores de academia foi de $44 \% .^{30}$

Frente ao exposto, podem-se identificar dois fatos relevantes. Primeiro, observa-se que, atualmente no Brasil, os índices de utilização desses produtos são bastante elevados. Esse fenômeno pode ser decorrente da falta de conhecimento de que uma alimentação balanceada e de qualidade atende às necessidades nutricionais de um praticante de exercícios físicos, e dispensa o uso de SA. ${ }^{31}$ Segundo, quanto mais recente a pesquisa, maior é o número de indivíduos que utilizam SA. De fato, todos os estudos tiveram caráter transversal, o que indica claramente a necessidade de adotar novos métodos de pesquisa, não só de seguimento, mas outros, como de Coorte, que estão sendo ignorados pelos pesquisadores deste tema.

\section{Suplementos Alimentares Mais Utilizados no Brasil}

Uma dieta balanceada deve conter quantidades adequadas de proteínas, vitaminas, gorduras e carboidratos suficientes para a obtenção dos resultados esperados, principalmente para indivíduos que visam o aumento de massa muscular com o treinamento resistido. ${ }^{32}$ No entanto, devido ao ritmo de vida agitado, excesso de treinamento, falta de horários adequados para realizar refeições, entre outros motivos, muitos indivíduos não conseguem ingerir uma dieta adequada às suas necessidades.

Por esses motivos, a suplementação alimentar vem se tornando bastante popular no universo das academias de ginástica, devido à praticidade de ingestão e os 
Tabela 1 - Prevalência Epidemiológica de Suplementos Alimentares e Esteroides Anabólicos Androgênicos no Brasil.

\begin{tabular}{|c|c|c|c|c|c|c|}
\hline Estudos & N/Faixa Etária & Sexo & Prevalência (\%) & Academias & Instrumento & Origem \\
\hline \multicolumn{7}{|c|}{ SUPLEMENTOS ALIMENTARES } \\
\hline Domingues \& Marins ${ }^{4}$ & $\begin{array}{c}200 \\
21 \text { a } 25 \text { anos }\end{array}$ & $181 \mathrm{H} / 19 \mathrm{M}$ & 94,0 & 19 & Questionário & Belo Horizonte \\
\hline Araújo e colaboradores ${ }^{15}$ & $\begin{array}{c}183 \\
21 \text { a } 23 \text { anos }\end{array}$ & $183 \mathrm{H} /$ & 34,0 & 14 & Questionário & Goiânia \\
\hline Pereira e colaboradores ${ }^{21}$ & $\begin{array}{c}309 \\
18 \text { a } 31 \text { anos }\end{array}$ & $57 \mathrm{H} / 17 \mathrm{M}$ & 23,9 & 7 & Questionário & São Paulo \\
\hline Santos \&Santos ${ }^{11}$ & $\begin{array}{c}100 \\
25 \text { a } 30 \text { anos }\end{array}$ & * & 70,0 & 10 & Questionário & Vitória \\
\hline Hallak e colaboradores ${ }^{13}$ & $\begin{array}{c}159 \\
25 \text { a } 30 \text { anos }\end{array}$ & $126 \mathrm{H} / 33 \mathrm{M}$ & 81,2 & * & Questionário & Belo Horizonte \\
\hline Silva e colaboradores ${ }^{22}$ & $\begin{array}{c}288 \\
28 \text { a } 38 \text { anos }\end{array}$ & $\begin{array}{l}188 \mathrm{H} / \\
100 \mathrm{M}\end{array}$ & 20,5 & 13 & Questionário & Porto Alegre \\
\hline Reis e colaboradores ${ }^{23}$ & $\begin{array}{c}246 \\
20 \text { a } 29 \text { anos }\end{array}$ & * & 50,6 & * & Questionário & Curitiba \\
\hline Pimenta\&Lopes ${ }^{17}$ & $\begin{array}{c}94 \\
27 \text { a } 34 \text { anos }\end{array}$ & $76 \mathrm{H} / 18 \mathrm{M})$ & 66,0 & 2 & Questionário & Cascavel \\
\hline $\begin{array}{l}\text { Hirschbruch e } \\
\text { colaboradores }^{10}\end{array}$ & $\begin{array}{c}201 \\
15 \text { a } 25 \text { anos }\end{array}$ & $\begin{array}{c}84 \mathrm{H} / \\
117 \mathrm{M})\end{array}$ & 61,2 & * & Questionário & São Paulo \\
\hline Rocha\&Pereira ${ }^{14}$ & $\begin{array}{c}160 \\
13 \text { a } 48 \text { anos }\end{array}$ & $\begin{array}{l}88 \mathrm{H} / \\
72 \mathrm{M}\end{array}$ & 32,0 & 10 & Questionário & Niterói e São Gonçalo \\
\hline \multicolumn{7}{|c|}{ ESTEROIDES ANABÓLICOS ANDROGÊNICOS } \\
\hline Silva \& Moreau ${ }^{8}$ & $\begin{array}{c}209 \\
25 \text { a } 29 \text { anos }\end{array}$ & $\begin{array}{l}146 \mathrm{H} / \\
63 \mathrm{M}\end{array}$ & 19,0 & 3 & Questionário & São Paulo \\
\hline Santos e colaboradores ${ }^{28}$ & $\begin{array}{c}58 \\
18 \text { a } 30 \text { anos }\end{array}$ & $58 \mathrm{H} /$ & 31,0 & 6 & Questionário & Aracajú \\
\hline Araújo e colaboradores ${ }^{15}$ & $\begin{array}{c}183 \\
18 \text { e } 26 \text { anos }\end{array}$ & $183 \mathrm{H}$ & 9,0 & 14 & Questionário & Goiânia \\
\hline Domingues \&Marins ${ }^{4}$ & $\begin{array}{c}200 \\
21 \text { a } 25 \text { anos }\end{array}$ & $181 \mathrm{H} / 19 \mathrm{M}$ & 94,0 & 19 & Questionário & Belo Horizonte \\
\hline Frizon e colaboradores ${ }^{7}$ & $\begin{array}{c}418 \\
21 \text { a } 25 \text { anos }\end{array}$ & $\begin{array}{c}347 \mathrm{H} / 71 \\
M\end{array}$ & 6,5 & 15 & Questionário & Erechim e Passo Fundo \\
\hline Silva e colaboradores ${ }^{22}$ & $\begin{array}{c}288 \\
28 \text { a } 31 \text { anos }\end{array}$ & $\begin{array}{c}188 \mathrm{H} / 100 \\
M\end{array}$ & 11,1 & 13 & Questionário & Porto Alegre \\
\hline Maior e colaboradores ${ }^{9}$ & $\begin{array}{c}506 \\
27 \text { a } 31 \text { anos }\end{array}$ & * & 24,9 & * & Questionário & Rio Grande do Sul \\
\hline Granjeiro e colaboradores ${ }^{12}$ & $\begin{array}{c}64 \\
18 \text { a } 25 \text { anos }\end{array}$ & * & 14,1 & * & Questionário & $\begin{array}{c}\text { Cidades de Minas } \\
\text { Gerais }\end{array}$ \\
\hline
\end{tabular}

$\mathrm{N}^{\circ}=$ Número total da amostra; *Não tem mencionado o número de academias; Percentual de prevalência em $\mathrm{H}=\mathrm{Homens} ; \mathrm{M}=\mathrm{Mulheres}$.

benefícios que são proporcionados. ${ }^{26}$ Isso ocorre, principalmente, porque indivíduos que praticam atividade física visam um melhor rendimento na forma física e/ ou ganho de saúde. De fato, segundo as pesquisas encontradas na presente revisão, $83,5 \%$ dos praticantes de musculação realizavam o consumo de suplementos à base de proteínas. ${ }^{4}$ Da mesma forma, Araújo e colaboradores ${ }^{33}$ relatam que, em Belém, $27 \%$ dos praticantes utilizavam suplementos à base de proteínas e aminoácidos.

Embora atualmente vários estudos demonstrem melhora no rendimento esportivo em função do consumo de SA e EAA, outros questionam seu uso e recomendam a realização de trabalhos que determinem a função e os efeitos desses produtos no organismo ${ }^{15}$, visto que estes produtos são, na maioria das vezes, utilizados de forma abusiva com o intuito de atingir objetivos em curto prazo. ${ }^{4}$ 
Tabela 2 - Perfil de Prevalência dos Suplementos Alimentares e Esteroides Anabólicos Androgênicos Mais Utilizados e Sua Indicação.

\begin{tabular}{|c|c|c|c|c|}
\hline Estudo & Suplementos Utilizados & Frequência (\%) & Indicação de Uso & Frequência (\%) \\
\hline \multicolumn{5}{|l|}{ SUPLEMENTOS ALIMENTARES } \\
\hline \multirow[t]{3}{*}{ Domingues \& Marins ${ }^{4}$} & Creatina & 89,0 & Professor e/ou amigo & 37,5 \\
\hline & Whey Protein & 83,5 & Nutricionista & 32,0 \\
\hline & Albumina & 82,0 & Vendedor & 12,5 \\
\hline \multirow[t]{3}{*}{ Araújo e colaboradores ${ }^{15}$} & Proteínas & 32,0 & Nutricionista & 19,0 \\
\hline & Creatina & 24,0 & Professor/Instrutor & 18,0 \\
\hline & Aminoácidos & 17,0 & Conta Própria & 18,0 \\
\hline \multirow[t]{5}{*}{ Pereira e colaboradores ${ }^{21}$} & Aminoácidos ou outros & 38,9 & Instrutor/professor/treinador & 31,1 \\
\hline & concentrados proteicos & & Amigos & 15,6 \\
\hline & & & Próprio individuo & 15,6 \\
\hline & $\begin{array}{l}\text { Vitaminas ou complexos } \\
\text { vitamínicos }\end{array}$ & 14,8 & & \\
\hline & Carboidratos & 11,1 & & \\
\hline Santos \& Santos ${ }^{11}$ & Aminoácidos & 66,0 & Professor & 33,0 \\
\hline \multirow[t]{3}{*}{ Hallak e colaboradores ${ }^{13}$} & $\begin{array}{l}\text { Aminoácidos ou concentrados } \\
\text { proteicos }\end{array}$ & 37,1 & * & * \\
\hline & Creatina & 28,6 & & \\
\hline & Carboidratos & 12,8 & & \\
\hline \multirow[t]{3}{*}{ Reis e colaboradores ${ }^{23}$} & Protéico & 22,3 & Auto-indicação & * \\
\hline & Creatina & 16,6 & Instrutores & \\
\hline & Aminoácidos & 10,3 & Nutricionistas & \\
\hline \multirow[t]{3}{*}{ Pimenta \& Lopes ${ }^{17}$} & Protéicos & 33,0 & Instrutor ou Ed. Físico & 43,0 \\
\hline & Aminoácidos & 30,0 & Nutricionista & 20,4 \\
\hline & Carboidratos & 19,0 & Amigos & 14,0 \\
\hline \multirow[t]{3}{*}{ Hirschbruch e colaboradores ${ }^{10}$} & Aminoácidos & 87,0 & Auto Prescrição & 42,8 \\
\hline & Proteínas & 61,0 & Indicação de Treinadores & 27,5 \\
\hline & Maltodextrina & 94,0 & & \\
\hline \multicolumn{5}{|c|}{ ESTEROIDES ANABÓLICOS ANDROGÊNICOS } \\
\hline \multirow[t]{3}{*}{ Silva \& Moreau ${ }^{8}$} & Estanozolol & 77,0 & Professor e/ou amigo & \\
\hline & Decanoato Nandrolona & 76,0 & Nutricionista & \\
\hline & Testosterona & 71,0 & Vendedor & \\
\hline \multirow[t]{3}{*}{ Araújo e colaboradores ${ }^{15}$} & Decanoato Nandrolona & 21,0 & Instrutor/professor & 11,0 \\
\hline & Oximentalona & 16,0 & Amigos & 11,0 \\
\hline & Testosterona & 13,0 & Meios de comunicação & 3,0 \\
\hline \multirow[t]{3}{*}{ Frizon e colaboradores $^{7}$} & Decanoato Nandrolona & 35,2 & * & \\
\hline & Testosterona & 17,6 & & \\
\hline & Estanozolol & 15,6 & & \\
\hline \multirow[t]{3}{*}{ Silva e colaboradores ${ }^{22}$} & Decanoato Nandrolona & 16,0 & * & * \\
\hline & Estanozolol & 15,0 & & \\
\hline & Testosterona & 10,0 & & \\
\hline \multirow[t]{3}{*}{ Maior e colaboradores ${ }^{9}$} & Decanoato Nandrolona & 55,0 & Recomendação de amigos & 44,0 \\
\hline & Testosterona & 53,0 & Auto-Medicação & 30,0 \\
\hline & Estanozolol & 40,0 & Internet & 15,0 \\
\hline
\end{tabular}

*Não mencionou o dado relacionado.

Um problema básico para a interpretação de resultados de diferentes trabalhos parece ser o entendimento sobre quais valores de ingestão de proteínas são considerados normais ou recomendados. A diretriz da Sociedade de Medicina do Esporte ${ }^{31}$, cujo informe sobre recomendações nutricionais tem sido considerado como referência em vários países, estipula para indivíduo sedentário um consumo de 0,8 a $1,2 \mathrm{~g} / \mathrm{kg}$ de peso para esportistas de 1,2 a $1,4 \mathrm{~g} / \mathrm{kg}$ de peso; atletas de endurance de 1,2 a $1,6 \mathrm{~g} / \mathrm{kg}$ de peso e atletas de força a partir 1,6 a 2,0g/ $/ \mathrm{kg}$ de peso. 
Dietas normais, que atendem às recomendações energéticas têm, em geral, de $10 \mathrm{a}$ $15 \%$ do valor energético total (VET) proveniente das proteínas.

Alguns autores têm sugerido que a ingestão de proteínas em torno de 15\% do VET é o suficiente para atender às necessidades de desportistas e atletas e que há poucas evidências científicas que justifiquem um consumo superior visando aumentar a massa muscular. ${ }^{34-36}$ Nesse sentido, não existem vantagens e sim alguns efeitos indesejáveis em aumentar a ingestão proteica acima de $2 \mathrm{~g} / \mathrm{kg}$ de peso corporal. ${ }^{37}$ Nissen $\&$ Sharp ${ }^{38}$, numa meta-análise sobre SA, ganho de força e massa magra, não encontraram efeito benéfico da suplementação proteica. Rennie $\&$ Tipton $^{39}$ mostraram que com o consumo de uma dieta de conteúdo normal de proteína (12-15\% do total de energia), mesmo atletas em treinamento não requerem qualquer suplementação proteica. $\mathrm{O}$ excesso de ingestão proteica pode, ainda, aumentar a produção de ureia, causar cólica abdominal e diarreia e aumentar o risco de desidratação..$^{40,41}$ Além disso, como a proteína é a principal fonte de produção ácida endógena através da excreção de sulfato, essa produção aumentada pode influenciar negativamente a densidade mineral óssea, se não for balanceada com uma dieta adequada (frutas e vegetais). ${ }^{42}$

Outra substância bastante utilizada pelos usuários de academia foi a creatina, cujo maior percentual encontrado foi de $89 \% .{ }^{4,15}$ Atualmente, a suplementação de creatina tem sido amplamente estudada, pesquisadores afirmam sua capacidade de aumentar a massa muscular ${ }^{43,44}$ principalmente, o volume das fibras tipo II; aumentar a força ${ }^{38}$ e a capacidade anaeróbica nos exercícios de alta intensidade. ${ }^{15}$ A dose de creatina habitualmente utilizada por atletas é de $20 \mathrm{~g} /$ dia por quatro a cinco dias (dose de ataque, ou saturação), seguida de 1-2 g/dia (dose de manutenção) por até três meses. ${ }^{34,45}$ Casey \& Greenhaff ${ }^{46}$ referiram que a suplementação nas doses usuais não causa alteração da função hepática ou renal. No entanto, com o uso prolongado, podem ocorrer, efeitos adversos: ganho de peso, desconforto gastrointestinal e câimbras musculares. ${ }^{34,47}$

Com relação aos aminoácidos, os dados da presente pesquisa apontaram no estudo de Santos \& Santos ${ }^{8}$ um percentual de 66\% dos indivíduos que utilizaram os aminoácidos como suplementação. Este fator pode ser explicado devido ao seu importante papel na produção de energia durante exercícios intensos, principalmente para evitar o acentuado catabolismo proteico e estimular a síntese proteica. ${ }^{15}$ Teoricamente, poderá estimular o ganho de massa muscular em resposta ao treinamento com pesos. Também é publicado em revistas factuais, folhetos e propagandas de alguns produtos, que suplementos com aminoácidos são úteis para halterofilistas e fisiculturistas, pois ajudam a driblar a fadiga e aumentar a massa muscular. $^{48}$

É importante ressaltar, ainda, que atualmente os novos tipos de suplementos que têm sido alvo de uso são os blends (termogênicos, pré-treinos, pós-treinos, workout), uma vez que os mesmos têm sido amplamente comercializados em sites e academias. Porém, curiosamente, estes suplementos não foram relatados nos estudos selecionados, e uma possível causa pode ser o seu custo de comercialização; como também podem ter ficado ocultos devido à baixa representatividade amostral dos estudos. Com base no site www.bodybuilding.com, esses produtos custam de 200 a 600 reais, de modo que são usados apenas por praticantes de academia de poder aquisitivo elevado. De fato, no estudo de Pereira e colaboradores ${ }^{19}$, os praticantes de musculação em academias possuíam um perfil socioeconômico de classe média baixa, o que corrobora com outros estudos que mostram a correlação entre o poder aquisitivo e o uso de SA. ${ }^{45}$ 
Com isso, podemos inferir que esses substratos são relevantes no processo de síntese proteica, e, consequentemente, importantes para atletas, idosos e praticantes de atividades físicas. No entanto, é preciso ponderar frente à grande quantidade de informações equivocadas provenientes de atletas e comerciantes acerca das virtudes das dietas ricas com esses substratos, tendo em vista que estas possuem um grande apelo mercadológico.

\section{Prevalência dos Esteroides Anabólicos Androgênicos no Brasil}

$\mathrm{O}$ estudo de Santos e Colaboradores ${ }^{24}$ identificou, na cidade de Aracajú, uma incidência de $31 \%$ de uso de EAA. Similarmente, outras pesquisas realizadas nas demais regiões demográficas do Brasil também encontraram predominância de alto percentual de uso. No Sudeste, foram encontrados percentuais de 14,1\% para as cidades de Poços de Caldas, Águas de Lindóia, Monte Sião e Espírito do Pinhal ${ }^{12}$, e um valor de 7,5\% para a cidade de Campinas. ${ }^{10}$ Prevalências maiores foram encontradas nas cidades de Caratinga e Rio de Janeiro, com valores respectivos de 20 e $33 \% .{ }^{25} \mathrm{Na}$ região Sul, pontualmente na cidade de Santa Maria, Macedo e colaboradores ${ }^{49}$ verificaram que apenas $2 \%$ dos indivíduos faziam uso dessas substâncias. Apesar de estar claro o aumento do uso desenfreado de EAA nas regiões do Brasil, é possível que estes dados estejam subestimados, uma vez que não foram demonstrados na metodologia desses estudos, meios que ajudassem os indivíduos a responderem o questionário de forma mais real, como estímulos para que as pessoas falassem sempre de forma coerente como era a real utilização dos EAA, e a garantia de um espaço reservado à entrevista. Portanto, os valores de prevalência podem ser bem maiores do que os detectados nesses estudos.

Esse uso excessivo de EAA pode ser vinculado à finalidade ergonômica e estética, sendo essa prática tendenciosa ou generalizada em algumas academias de ginástica. ${ }^{31}$ Além disso, esse fenômeno também pode estar relacionado à influência do meio da nutrição esportiva, devido ao fato de os indivíduos acreditarem que esses produtos lhe darão maior vantagem estética quando, na verdade, podem torna-se prejudiciais à saúde, com o aumento do risco de desenvolvimento de patologia cardiovascular. De fato, pesquisas recentes demonstram que o uso abusivo de EAA em atletas de força pode levar até a morte devido a alterações como: disfunção ventricular ${ }^{50}$, fibrose e morte de miócitos no ventrículo esquer$\mathrm{do}^{51}$, desintegração das fibras musculares cardíacas e perda de discos intercalares e bandas- $Z{ }^{52}$

Em relação às substâncias relatadas pelos usuários de EAA, os estudos demonstram que a Decanoato de Nandrolona ${ }^{53,54}$ corresponde a $76 \%$ de utilização pelos adeptos de musculação, seguida pela Testosterona ${ }^{53,54}$ (71\%) e Estanozolol ${ }^{53,}$ ${ }^{54}(77 \%)^{8}$, ainda podendo permutar a ordem de preferência pelos usuários. Isso pode ser decorrente de uma maior acessibilidade, menor custo no comércio, maior divulgação e ou pelas diferenças culturais entre as regiões brasileiras.

Devido a suas propriedades anabólicas e mínima toxicidade ao fígado, o preparo anabólico injetável, Decanoato de Nandrolona, também chamado de 19-nortestosterona, é o EAA mais utilizado e com grande popularidade entre os praticantes de musculação que desejam aumentar a massa muscular, pois se torna um esteroide mais anabólico que androgênico, devido a um reduzido potencial de conversão para o Estradiol.Alguns estudos apontam que essa substância apresenta efeitos anticatabólico e poupador de proteína, efeitos favoráveis no metabolismo de cálcio, aumento da massa óssea e muscular em indivíduos debilitados, como também no tratamento de doenças como HIV e osteoporose. 
Com incidências de 17,6, 53 e 71\% nos estudos encontrados, a Testosterona ${ }^{53,54}$ é indicada para a terapia de reposição hormonal masculina, a testosterona cristalizada possui em sua formulação quatro ésteres diferentes: propienato, fenilpropionato, isocaproato e caproato. Dessa forma, é capaz de fornecer grandes resultados como aumento de força e ganho de peso. ${ }^{56,57}$ Por apresentar uma característica peculiar de não promover a retenção hídrica como a maioria dos esteroides altamente androgênicos, pode-se atribuir a estes fatores, a preferência dessas substâncias para o uso entre os praticantes de musculação.

A Estanozolol é uma marca popular de esteroide, que pode ser encontrada nas formas oral e injetável. Estudos têm demonstrado que este esteroide apresenta uma tendência ligeiramente maior para o crescimento muscular do que a atividade androgênica, sendo assim um anabolizante que exibe um baixo efeito colateral sob este aspecto. ${ }^{57}$ Por isso, suas incidências de uso encontradas foram de $77,40,15,7 \% \%^{7-9}$

A prevalência das formas de indicações de uso dos EAA na presente pesquisa foi de $37,5 \%$ para professores ou instrutores de academia e $44 \%$ por recomendações de amigos, além de $30 \%$ de incidência por automedicação. ${ }^{4,9,15}$ Porém, estas substâncias só podem ser prescritas por médicos e dentistas, segundo a Lei no. 9.965, de 27 de abril de 2000, e a obtenção destas em estabelecimentos farmacêuticos somente deveria ser realizada por meio de receituário médico devidamente preenchido.

Entretanto, inúmeros EAA entram clandestinamente no país e são comercializados livremente na internet e nas academias de ginástica. Fator agravante reside no fato de que há pouca fiscalização quanto à autenticidade das receitas médicas e laboratórios clandestinos. Nestes laboratórios, muitos esteroides são falsificados, utilizam-se ampolas não esterificadas ou, muitas vezes, faz-se a mistura com outras drogas. Assim, as indicações não provenientes de profissionais clínicos especializados podem trazer malefícios irreversíveis, pois os indivíduos estão arriscando sua própria saúde em detrimento de alcançar os objetivos do culto ao corpo em curto espaço de tempo.

\section{Indicação de Uso}

A suplementação alimentar é indicada quando o organismo necessita de complementação na alimentação. No entanto, a suplementação feita sem necessidade $\mathrm{e}$ sem orientação de um profissional da área especializada, pelo que se observa na presente revisão, é ordinária. De fato, os estudos da presente revisão apontaram que a fonte de indicação, ou seja, prescrição de SA foi realizada, prioritariamente por instrutores/professores, cujos percentuais encontrados foram de 43, 37,5, $33 \mathrm{e}$ $31,1 \%$ respectivamente. ${ }^{4,11,17,21}$ Por atuarem diretamente dentro das academias, os professores vêm sendo requisitados a prestarem orientações de dietas e/ou utilização de recursos ergogênicos ${ }^{48}$, mas eles não devem prestar este tipo de orientação. Os profissionais mais indicados para sugerir o uso dessas substâncias são os nutricionistas, cujos percentuais encontrados nos estudos da nossa revisão foram de 32, 20,4 e 19\%, sendo menores percentuais para os profissionais de educação física., ${ }^{4}, 15$

Nossos resultados mostram ainda que é preciso elucidar melhor as informações para os consumidores, uma vez que nos presentes estudos houve indicação de uso dos recursos ergogênicos por meio de amigos (15,6\%) e por conta própria (18\%), o que caracteriza um perfil de utilização sem orientação e acompanhamento adequados. ${ }^{15,21}$ Contudo, sabe-se que essa faceta pode ser explicada pelo mercado que age no interior das academias de ginástica e musculação, pois se observa que muitos instrutores recebem comissão para a venda de suplementos, e não possuem conhecimento suficiente para tal recomendação. ${ }^{58}$ 
Assim, faz-se necessário alertar os frequentadores de academia de que os SA devem ser prescritos de forma adequada apenas por profissionais habilitados, que precisam mensurar o gasto energético de cada indivíduo, e fazer a prescrição de uma dieta equilibrada para cada objetivo, de acordo com a intensidade e volume de trabalho diário.

\section{Benefícios e Efeitos Adversos do Uso de Esteroides Anabólicos Androgênicos no Brasil}

A tabela 3 apresenta, detalhamente, o percentual de frequência de relatos com relação aos benefícios e efeitos adversos do uso de EAA. Os esteroides foram inicialmente desenvolvidos, na década de 1930, visando elevar a agressividade dos soldados que estavam em combate na segunda guerra mundial. ${ }^{57,59} \mathrm{Em}$ seguida, seu uso foi direcionado à terapêutica, no tratamento de pacientes com deficiência natural de andrógenos, anemias atípicas, no tratamento da osteoporose, na recuperação de grandes cirurgias, e no tratamento de queimaduras e do câncer de mama. ${ }^{7,18,19} \mathrm{O}$ uso dos EAA teve destaque no meio esportivo, devido às propriedades anabólicas que promovem o aumento da massa muscular, desenvolvimento da força e velocidade de recuperação dos músculos; auxilia no controle dos níveis de gordura corporal, e melhora o desempenho físico do atleta. ${ }^{60}$ Atualmente, o seu uso tem sido desvirtuado, de forma que, sua utlização tem como foco a estética corporal, cujo objetivo predominante é o ganho de massa muscular e perda de gordura corporal.

Dentre os benefícios relatados com o uso dos EAA, grande parte dos estudos realizados com os praticantes de musculação menciona utilizá-los com a finalidade de melhoria na estética corporal. Silva e colaboradores ${ }^{60}$ observaram que 92,3\%

Tabela 3 - Frequência de Benefícios e Efeitos Adversos Apresentados Pelos Sujeitos Após Uso de EAA.

\begin{tabular}{|c|c|c|c|c|}
\hline Estudo & Benefícios c/ uso de EAA & Frequência (\%) & Efeitos Adversos & Frequência (\%) \\
\hline \multirow[t]{3}{*}{ Silva \& Moreau ${ }^{8}$} & Estética & 82,0 & Alteração de Humor & 54,0 \\
\hline & Saúde & 41,0 & Agressividade & 49,0 \\
\hline & & & Acne & 46,0 \\
\hline \multirow[t]{3}{*}{ Santos e colaboradores ${ }^{28}$} & Ganho de Força & 32,0 & * & * \\
\hline & Não gera Benefícios & 30,0 & & \\
\hline & Aumento da Performance & 13,0 & & \\
\hline \multirow[t]{2}{*}{ Araújo e colaboradores ${ }^{15}$} & * & * & Agressividade & 81,0 \\
\hline & & & Acne & 94,0 \\
\hline \multicolumn{5}{|l|}{ Domingues \& Marins ${ }^{4}$} \\
\hline \multirow[t]{4}{*}{ Frizon e colaboradores ${ }^{7}$} & Estética & * & Agressividade & 6 \\
\hline & Ganho de Força & & Alteração de humor & 4 \\
\hline & & & Pressão alta & 4 \\
\hline & & & Acne & \\
\hline \multirow[t]{3}{*}{ Silva e colaboradores ${ }^{22}$} & Estética & 92,3 & Alteração & 73,3 \\
\hline & Saúde & 64,1 & Irritabilidade e Agressividade & 53,3 \\
\hline & Aumento da Performance & 25,6 & Aumento ou Diminuição da Libido & 43,3 \\
\hline \multirow[t]{3}{*}{ Maior e colaboradores ${ }^{9}$} & Estética & 58,0 & Agressividade & 47,0 \\
\hline & & & Aument. Desempenho sexual & 46,0 \\
\hline & & & Retenção hídrica & 39,0 \\
\hline \multirow[t]{2}{*}{ Granjeiro e colaboradores ${ }^{12}$} & * & & Desconhecem & 35,1 \\
\hline & & & Não trazem efeitos colaterais & 28,4 \\
\hline
\end{tabular}

*Não mencionou qualquer dado 
obtiveram tais benefícios. Porém, com relação à literatura vigente, os dados ainda são conflitantes, uma vez que, enquanto alguns estudos apontam que há benefí$\operatorname{cios}^{9,25,60}$, outros não identificaram efeito. ${ }^{25}$

Apesar de alguns estudos relatarem benefícios com a utilização dos EAA, o uso desenfreado dessas substâncias pode ser prejudicial, como observado na tabela 3 . Lise e colaboradore ${ }^{19}$ afirmam que o uso ilícito faz com que os usuários utilizem centenas de doses a mais do que aquela recomendada para finalidades terapêuticas. Diante disso, os estudos abordados na presente revisão demonstram que os efeitos colaterais predominantes envolvem desde o surgimento de acne até alterações psicológicas. De fato, os resultados apresentados por Araújo e colaboradores ${ }^{15} \mathrm{e}$ Silva \& Moreau $^{8}$ indicam que de 46 a 94\% dos praticantes de musculação, que faziam uso dos EAA, foram acometidos por acne. Já para o comportamento psicológico, verificou-se um percentual de agressividade ou ansiedade de 47 a $73 \%$ após uso prolongado de EAA. ${ }^{8,9,60}$ Estudos relacionam que o mau uso destas substâncias está inteiramente atrelado à variação de humor, incluindo irritabilidade e agressividade. ${ }^{61,62}$ Vale salientar ainda que em nenhum desses estudos houve a preocupação de avaliar algum tipo de efeito adverso implicado pelo consumo de SA. Mesmo assim, isso é algo que também merece atenção, devido a alguns indícios reportados pela literatura acerca da possibilidade de que suplementos esportivos tragam problemas renais e hepáticos. ${ }^{63}$

Ainda nesta perspectiva de efeitos adversos dos esteroides, a literatura traz diversos malefícios causados pelo uso abusivo dos EAA. Maravelias e colaboradores ${ }^{64}$ discutem que altas e repetidas doses de EAA podem levar às lesões graves e irreversíveis nos órgãos do corpo humano. Entre os efeitos adversos mais comuns estão alterações cerebrovasculares, endócrinas, renais, imunológicas, musculoesqueléticas, redução da fertilidade, ginecomastia em homens, masculinização de mulheres e crianças, hipertensão, aterosclerose, icterícia, neoplasias hepáticas, carcinoma, danos no tendão, distúrbios comportamentais e psiquiátricos. Dados preocupantes demonstram que nem todos os efeitos adversos são constatados como sintomatologia, por isso, os dados fornecidos em estudos de prevalência relatada ainda são muito limitados, uma vez que a maioria dos efeitos adversos só pode ser constatada clinicamente. Vicencio e colaboradores ${ }^{65}$ ainda acrescentam que os EAA levam a um aumento intracelular de $\mathrm{Ca}^{2+} \mathrm{e}$ devido à versatilidade do $\mathrm{Ca}^{2+}$ como segundo mensageiro em uma diversidade de tipos de células, incluindo osteoblastos, plaquetas, células musculares esqueléticas, miócitos cardíacos e neurônios, o $\mathrm{Ca}^{2+}$ pode fornecer diversas respostas, o que leva um grande número de implicações fisiopatológicas.

Desta forma, todos esses estudos indicam que há necessidade de fiscalização rigorosa sobre o uso dos EAA com a finalidade de evitar malefícios tanto de ordem psicológica, quanto morfológica e fisiológica. Esses dados obtidos são de grande importância para mostrar e orientar a população e profissionais atuantes da área de saúde sobre a implantação de ações e projetos que contribuam na orientação de praticantes de exercício físico quanto ao uso de SA e EAA sem acompanhamento adequado, e abordar os possíveis prejuízos causados por eles.

\section{CONCLUSÃO}

A presente revisão nos permite concluir que tanto o consumo de SA quanto o uso dos EAA se encontram exacerbados nas academias brasileiras, principalmente na região Sudeste. Além disso, o uso abusivo dos EAA ocorre devido à falta de infor- 
mações sobre suas contraindicações, repercutindo em inúmeros efeitos adversos à saúde. Assim, os resultados fornecem subsídios para o entendimento de um grave problema de saúde pública com características epidemiológicas, e atenta para a necessidade de medidas eficientes e adequadas no desenvolvimento de programas de prevenção nas áreas de saúde, além de programas de educação nutricional direcionados a populações específicas.

\section{Agradecimentos/Financiamento}

Agradecemos aos autores dos estudos incluídos nesta revisão, que contribuíram com suas informações. Salientamos ainda que a presente revisão não possui, fonte de financiamento.

\section{Contribuição dos Autores}

Fabiana Ranielle de Siqueira Nogueira foi genitora da ideia deste trabalho e contribuiu com a escrita. Alesandra Araújo de Souza contribuiu com a escrita, colocação do artigo dentro das normas e elaboração dos documentos necessários para a submissão. Aline de Freitas Brito orientou este trabalho e contribuiu na elaboração, correção da escrita e revisão da última versão deste manuscrito.

\section{REFERÊNCIAS}

1. Nazar F. O uso de recursos ergogênicos por indivíduos praticantes de musculação nas academias de Irati, PR. Revista Digital Buenos Aires. 2011;154.

2. Moraes Miguel F, Alexandre Grings L, Borges Pereira G, et al. Different cardiovascular responses to a resistance training session in hypertensive women receiving propanolol compared with normotensive controls. The Scientific World Journal. 2012;2012:913271. Epub 2012/05/31.

3. Del Corral P, Chandler-Laney PC, Casazza K, et al. Effect of dietary adherence with or without exercise on weight loss: a mechanistic approach to a global problem. The Journal of Clinical Endocrinology and Metabolism. 2009;94(5):1602-7. Epub 2009/03/05.

4. Domingues SF, Marins J. Utilização de recursos ergogênicos e suplementos alimentares por praticantes de musculação em Belo Horizonte - MG. Fitness e Performance Journal. 2007;6(4):218-26.

5. Applegate EA, Grivetti LE. Search for the competitive edge: a history of dietary fads and supplements. The Journal of Nutrition. 1997;127(5 Supp1):869S-73S. Epub 1997/05/01.

6. Brasil, Portaria SVS/MS n²22, de Março de 1998. Regulamento Técnico para Fixação de Identidade e Qualidade de Alimentos para Praticantes de Atividade Física.

7. Frizon F,Macedo SMD, Yonamine, M.Uso de esteroides andrógenos anabólicos por praticantes de atividade física das principais academias de Rechim e Passo Fundo/RS

8. Revista de Ciências Farmacêuticas Básica Aplicada. 2005;26(3):227-32.

9. Silva LSMF, Moreau RLDM. Uso de esteroides anabólicos androgênicos por praticantes de musculação de grandes academias da cidade de São Paulo. Revista Brasileira de Ciências Farmacêuticas. 2003;39(3):327-33.

10. Maior AS, Bernasconi A, Sanches J F, Simão RMP, Miranda H, Nascimento MJH. Uso de esteroides anabólicos em duas cidades do Rio Grande do Sul. Revista Brasileira de Prescrição e Fisiologia do Exercício. 2009;3(18):580-91.

11. Hirschbruch MD, Fisberg M, Mochizuki L. Consumo de suplementos por jovens freqüentadores de academias de ginástica em São Paulo. Revista Brasileira de Medicina do Esporte. 2008;14(6):539-43.

12. Santos MÂAD, Santos RPD. Uso de suplementos alimentares como forma de melhorar a performance nos programas de atividade física em academias de ginástica. Revista Paulista de Educação Física. 2002;16(2):174-85.

13. Granjeiro PA, Costa CER, Barros, AR, Inácio, RF. Levantamento do uso de anabolizantes e suplementos nutricionais em academias de musculação. Movimento e Percepção. 2008;9:287-99. 
14. Hallak A, Fabrini S, Peluzio MCG. Avaliação do consumo de suplementos nutricionais em academias da zona sul de Belo Horizonte, $\mathrm{MG}$, Brasil. Revista Brasileira de Nutrição Esportiva. 2007;1(2):55-60.

15. Rocha LPD, Pereira MVL. Consumo de suplementos nutricionais por praticantes de exercícios físicos em academias. Revista de Nutrição. 1998;11(1):76-82.

16. Araújo LRD, Andreolo J, Silva MS. Utilizaçäo de suplemento alimentar e anabolizante por praticantes de musculaçäo nas academias de Goiânia-GO. Revista Brasileira de Ciências e Movimento. 2002;Jul;10(3):13-8.

17. Hirschbruch MD CJ. Nutrição esportiva: uma visão prática. A nutrição em academias aspectos práticos. São Paulo: Manole, 2002, 123-58.

18. Pimenta MG, Lopes A. Consumo de suplementos nutricionais por praticantes de atividade física de academia de ginástica de Cascavel-PR. Simpósio Celafiscs. 2007.

19. Rocha FL, Roque FR, Oliveira EM. Esteroides anabolizantes: mecanismos de ação e efeitos sobre o sistema cardiovascular. Mundo Saúde. 2007;31(4):470-7.

20. Lise MLZ, Silva TSDG, Ferigolo M, Barros HMT. O abuso de esteroides anabólicoandrogênicos em atletismo. Revista da Associação Médica Brasileira. 1999;45(4):364-70.

21. Bennett S, Bennett JW. The process of evidence-based practice in occupational therapy: Informing clinical decisions. Used with permission: Australian Occupational Therapy Journal 2000;47 171-80.

22. Pereira RF, Lajolo FM, Hirschbruch MD. Consumo de suplementos por alunos de academias de ginástica em São Paulo. Revista de Nutrição. 2003;16(3):265-72.

23. Silva PRPD, Machado Júnior LC, Figueiredo VC, Cioffi AP, Prestes MC, Czepielewski MA. Prevalência do uso de agentes anabólicos em praticantes de musculação de Porto Alegre. Arquivos Brasileiros de Endocrinologia \& Metabologia. 2007;51(1):104-10.

24. Reis MGA, Manzoni M, Simonard-Loureiro H. Avaliação do uso de suplementos nutricionais por frequentadores de academias de ginástica em Curitiba. Revista Nutrição Brasil 2006;5:56-61.

25. Santos MCF, Siqueira, RCL, Aguiar JA, Pereira HNP, Sousa FR, Gurgel LA. Uso de suplementos nutricionais e agentes ergogênicos por praticantes de musculação de duas academias de Fortaleza-CE. Revista Brasileira de Educação Física e Esporte. 2006;20:395-401.

26. Silva Junior SHA, Souza I, Silva JHA, Oliveira JW, Souza MA. Perfil de atletas de academia: o uso de anabolizantes e suplementos nos programas de atividade física. Revista Digital Buenos Aires. 2008;119.

27. De Rezende G, Mariana,TJ. Relação de alguns suplementos nutricionais e o desempenho físico. Archivos Latinoamericanos de Nutrición. 2000;50(4):317-29.

28. Hildebrandt T, Langenbucher JW, Lai JK, Loeb KL, Hollander E. Development and validation of the appearance and performance enhancing drug use schedule. Addictive Behaviors. 2011;36(10):949-58. Epub 2011/06/07.

29. Santos AF, Mendonça PMH, Santos LDA, Silva NF, Tavares JKL. Anabolizantes: conceitos segundo praticantes de musculação em Aracaju (SE). Psicologia em Estudo 2006;11(2):371-80.

30. Lollo PCB, Tavares MCGC. Perfil dos consumidores de suplementos dietéticos nas academias de ginástica de Campinas, SP. Revista Digital Buenos Aires. 2004;76:10-5.

31. Zeiser CC, Silva RCR. O uso de suplementos alimentares entre os profissionais de Educação Física atuantes em academias da cidade de Florianópolis. Revista Nutrição em Pauta. 2007.

32. Hernandez AJ, Nahas RM. Modificações dietéticas, reposição hídrica, suplementos alimentares e drogas: comprovação de ação ergogênica e potenciais riscos para a saúde. Revista Brasileira de Medicina do Esporte. 2009;15(3,supl.0):3-12.

33. Guimarães Neto,WM. Musculação: Anabolismo Total: nutrição, treinamento, uso de esteroides anabólicos e outros ergogênicos. Guarulhos: Phorte,1999.

34. Araújo ACMD, Soares YDNG. Perfil de utilização de repositores proteícos nas academias de Belém, ParáPattern of utilization of protein supplements in academies in Belém, Pará. Revista Nutrição 1999;12(1):81-9.

35. Calfee R, Fadale P. Popular ergogenic drugs and supplements in young athletes. Pediatrics. 2006;117(3):e577-89. Epub 2006/03/03.

36. Kreider RB. Effects of creatine supplementation on performance and training adaptations. Molecular and Cellular Biochemisty. 2003;244(1-2):89-94. Epub 2003/04/19.

37. Lemon PW. Is increased dietary protein necessary or beneficial for individuals with a physically active lifestyle? Nutrition Review. 1996;54(4 Pt 2):S169-75. Epub 1996/04/01. 
38. Odriozola J. Nutrición y desporto. Madri: Ediciones de la Universa,1988.

39. Nissen SL, Sharp RL. Effect of dietary supplements on lean mass and strength gains with resistance exercise: a meta-analysis. Journal of Applied Physiology (Bethesda, Md : 1985). 2003;94(2):651-9. Epub 2002/11/16.

40. Rennie MJ, Tipton KD. Protein and amino acid metabolism during and after exercise and the effects of nutrition. Annual Review of Nutrition 2000;20:457-83. Epub 2000/08/15.

41. Chromiak JA, Antonio J. Use of amino acids as growth hormone-releasing agents by athletes. Nutrition. 2002;18(7-8):657-61. Epub 2002/07/03.

42. Cotunga N, Vickery CE, McBee S. Sports nutrition for young athletes. Journal School Nursing. 2005;21(6):323-8. Epub 2006/01/20.

43. Millward DJ. Protein and amino acid requirements of athletes. Journal Sports Sciences. 2004 Jan;22(1)(0264-0414 (Print)):143-4.

44. Volek JS, Mazzetti SA, Farquhar WB, Barnes BR, Gomez AL, Kraemer WJ. Physiological responses to short-term exercise in the heat after creatine loading. Medicine and Science Sports and Exercise 2001;33(7):1101-8. Epub 2001/07/11.

45. Branch JD. Effect of creatine supplementation on body composition and performance: a metaanalysis. International Journal of Sport Nutrition and Exercise Metabolism. 2003;13(2):198226. Epub 2003/08/30.

46. DesJardins M. Supplement use in the adolescent athlete. Current Sports Medicine Reports. 2002;1(6):369-73. Epub 2003/07/02.

47. Casey A, Greenhaff PL. Does dietary creatine supplementation play a role in skeletal muscle metabolism and performance? The American Journal of Clinical Nutrition. 2000;72(2 Suppl):607S-17S. Epub 2000/08/02.

48. Maughan RJ, King DS, Lea T. Dietary supplements. Journal Sports Science 2004;22(1):95113. Epub 2004/02/20.

49. Júnior LS, Borelli M. Você pergunta: suplementos esportivos. Forma Física. 1994;2:46-8.

50. Macedo CLD, Santos RP, Pasqualotto AC, Capette F R, Pereira SM, Casagrande A, Moletta DC, Fuzer J, Lopes SAV.Uso de esteroides anabolizantes em praticantes de musculação e/ou fisioculturismo. Revista Brasileira de Medicina do Esporte. 1998;4 (1):13-7.

51. Luijkx T, Cramer MJ, Prakken NH, Buckens CF, Mosterd A, Rienks R, et al. Sport category is an important determinant of cardiac adaptation: an MRI study. British Journal of Sports Medicine. 2012. Epub 2012/01/06.

52. Saba L, Montisci R, Raz E, Sanfilippo R, Suri JS, Piga M. Association between Carotid Artery Plaque Type and Cerebral Microbleeds. American Journal of Neuroradiology. 2012. Epub 2012/05/26.

53. Hasan MK, Kabir AKL, Mistry S. Chemical and Biological Investigation of Leaves of Polygonum plebejum. Journal of Pharmaceutical Sciences. 2009;2(2):66-71.

54. Dicionário de Especialidades Farmacêuticas - DEF Produção: Jornal Brasileiro de Medicina,1999/2000.

55. Grunding PB, M. World Anabolic Review 1996: Houst, MB Muscle Books; 1995.

56. Boff SR. Efeitos colaterais dos esteroides anabolizantes sintéticos. Revista Brasileira de Ciência e Movimento. 2008;16:123-7.

57. Guimarães Neto WM, Peres RAN. Guerra metabólica manual de sobrevivência. São Paulo: Phorte,2005.

58. Santos AM. O mundo anabólico: análise do uso de esteroides anabólicos nos esportes. Barueri: Manole,2007.

59. Brossi F. Orientação Nutricional: Avaliação do conhecimento de Estudantes de Educação Física quanto à Nutrição e Orientação Nutricional. Revista Nutrição em Pauta. 2000.

60. Ferreira UMG, Ferreira ACD, Azevedo AMP, Medeiros, RL, Silva, CAB. Esteroides Anabólicos Androgênicos. Revista Brasielira em Promoção da Saúde. 2007;20 (4):267-75.

61. Silva JAC, Silva Junior JP, Feitosa WM. Transtorno dismórfico muscular na prática de atividades esportivas. Caderno de Pesquisa em Saúde. 2007;1.

62. Yesalis CE, Kennedy NJ, Kopstein AN, Bahrke MS. Anabolic-androgenic steroid use in the United States. The Journal of The American Medical Association. 1993;270(10):1217-21. Epub 1993/09/08.

63. Silva PRPD, Danielski R, Czepielewski MA. Esteroides anabolizantes no esporte 
64. Anabolic steroids in sports. Revista Brasileira de medicina do Esporte. 2002;8(6):235-43.

65. Stickel F, Kessebohm K, Weimann R, Seitz HK. Review of liver injury associated with dietary supplements. Liver international: Official Journal of The International Association For The Study of The Liver. 2011;31(5):595-605. Epub 2011/04/05.

66. Maravelias C, Dona A, Stefanidou M, Spiliopoulou C. Adverse effects of anabolic steroids in athletes. A constant threat. Toxicology Letters. 2005;158(3):167-75. Epub 2005/07/12.

67. Vicencio JM,Estrada M, Galvis D, Bravo R, Contreras AE, Rotter D, et al. Anabolic androgenic steroids and intracellular calcium signaling: a mini review on mechanisms and physiological implications. Mini Reviews in Medicinal Chemistry. 2011;11(5):390-8. Epub 2011/03/30.

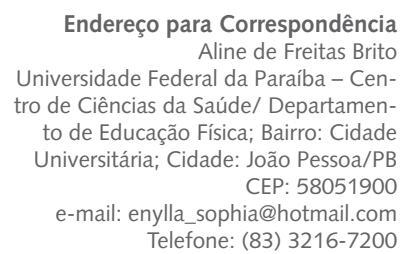

$$
\begin{array}{ll}
\text { Recebido } & 12 / 03 / 2012 \\
\text { Revisado } & 21 / 03 / 2012 \\
& 22 / 06 / 2012 \\
& 12 / 08 / 2012 \\
& 21 / 09 / 2012 \\
\text { Aprovado } & 09 / 10 / 2012
\end{array}
$$

